\title{
Disruptive Technologies for Efficient and Sustainable Smart Cities
}

\author{
Dipak S. Gade \\ Post-Doctoral Research Scholar, Department of Computer Science and Engineering, \\ Srinivas University, Mangalore, India \\ ORCID ID: 0000-0002-0962-0375, Email: dipak.pdf@ srinivasuniversity.edu.in
}

Area/Section: Technology Management.

Type of the Paper: Review Based Research.

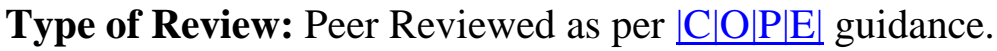

Indexed in: OpenAIRE.

DOI: https://doi.org/10.5281/zenodo.5221206

Google Scholar Citation: IJMTS

\section{How to Cite this Paper:}

Gade, Dipak S., (2021). Disruptive Technologies for Efficient and Sustainable Smart Cities. International Journal of Management, Technology, and Social Sciences (IJMTS), 6(2), 47-63. DOI: https://doi.org/10.5281/zenodo.5221206

International Journal of Management, Technology, and Social Sciences (IJMTS)

A Refereed International Journal of Srinivas University, India.

CrossRef DOI: https://doi.org/10.47992/IJMTS.2581.6012.0152

(C) With Author.

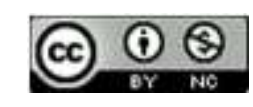

This work is licensed under a Creative Commons Attribution-Non-Commercial 4.0 International License subject to proper citation to the publication source of the work.

Disclaimer: The scholarly papers as reviewed and published by the Srinivas Publications (S.P.), India are the views and opinions of their respective authors and are not the views or opinions of the SP. The SP disclaims of any harm or loss caused due to the published content to any party. 


\title{
Disruptive Technologies for Efficient and Sustainable Smart Cities
}

\author{
Dipak S. Gade \\ Post-Doctoral Research Scholar, Department of Computer Science and Engineering, \\ Srinivas University, Mangalore, India \\ ORCID ID: 0000-0002-0962-0375, Email: dipak.pdf@ srinivasuniversity.edu.in
}

\begin{abstract}
Purpose: The most active and rapid development in today's world is happening in Smart cities. Smart Cities are changing very fast in every aspect, be it development, operations, and or maintenance points of view. Today's Smart Cities are aiming to be at an advanced stage of urbanization and fully exploiting digital infrastructure for rapid urban development. In order to make the cities better places to live and to offer more comfortable and enjoyable living for their residents, Smart Cities are using and employing various tools and technologies to make themselves smarter and more connected with their stakeholders using technology means. Industry 4.0, Digital Transformation, and various latest technologies such as 5G, Data Analytics, IoT, AI, and Machine Learning, Digital Twins, etc. are transforming and shaping up Smart Cities in never before style. In this paper, various such key technologies that are positively affecting Smart Cities are discussed at length. It is also highlighted in detail how these technologies are impacting Smart Cities development and operations. Finally, future research directions are also discussed in brief.
\end{abstract}

Design/Methodology/Approach: Extensive exploration of available literature with research papers, conference papers, white papers, online blogs, dedicated websites, etc. on the research area and interactions with field researchers, subject matter experts, industry professionals is carried out to collect, analyse and process the collected data to find out the facts. The resulted facts and findings about the latest technologies used in Smart Cities is presented in this research paper.

Findings/Result: After analysis of available literature and based on interactions with relevant stakeholders and based on own data analysis, it is identified that Smart City services are making use of various latest tools and technologies to solve their real-life challenges. Among vast list of technologies specifically IoT, Blockchain, Digital Twins, 5G, Contactless Technology, AI and ML are found the most significant and widely used technologies in Smart Cities development, operations, and maintenance activities.

Originality/Value: It is found that not many research papers are available on analysis of future technologies used in Smart Cities. The data presented in this paper is genuine and original and completely based on systematic literature review, interactions with SME, Researchers and Industry experts and based on own data analysis which produced new findings.

Paper Type: Technology oriented Research

Keywords: 5G, Digital Twins, Blockchain, Smart City, IoT, NFC, AI, ML

\section{INTRODUCTION :}

Smart Cities are rapidly evolving, and various new Smart Cities are getting established across the globe. India is also not behind in the race. In fact, the Indian Government has made a mission to convert at least 100 existing cities as Smart Cities in the next few years, as per Smart City Mission [1]. Also, various other developing countries across the globe are setting up either new Smart Cities or converting existing cities into Smart Cities. Before deep diving further, let us try to understand what the Smart City concept is and how Smart Cities are making the life of its residents enjoyable and comfortable.

First of all, let me clear you that there is no standard worldwide accepted definition of Smart City [1]. The smart Cities concept has become popular over last one to two decades, however, well-planned, and 
engineered cities were setup and established from a long time. In today's industry 4.0 era, the cities have become smarter using and employing various latest technologies, tools, and IT infrastructures. Therefore, based on infrastructure, tools, and technologies employed, its resident's culture and willingness to change, the conceptualization of Smart City may differ from country to country, and from one city to another. In general, however, it is agreed by many people that Smart Cities are designed, developed, driven, managed, and operated with the latest Information Communication and Digital Technologies [2]. In a similar way, Smart Cities Council has provided a very straightforward definition for Smart City as "A smart city is one that has digital technology embedded across all city functions".

After going through various research papers on Smart Cities and interacting with Smart Cities consultants and SMEs, I personally feel that Smart City is that city which provides smart services to its citizens to make their life more comfortable, safe, and happy. Please refer to below figure which has presented a typical Smart City block diagram. priority. As presented in figure 1, Smart City is based on smart building infrastructure and facilitates various smart services including educations, medical facilities, city administration, Traffic management, waste disposal, green environment, ample parking, energy and power, economy, entertainment, etc. For all these services and operations, Smart City focuses on its key objectives and actively utilizes latest technologies and tools.

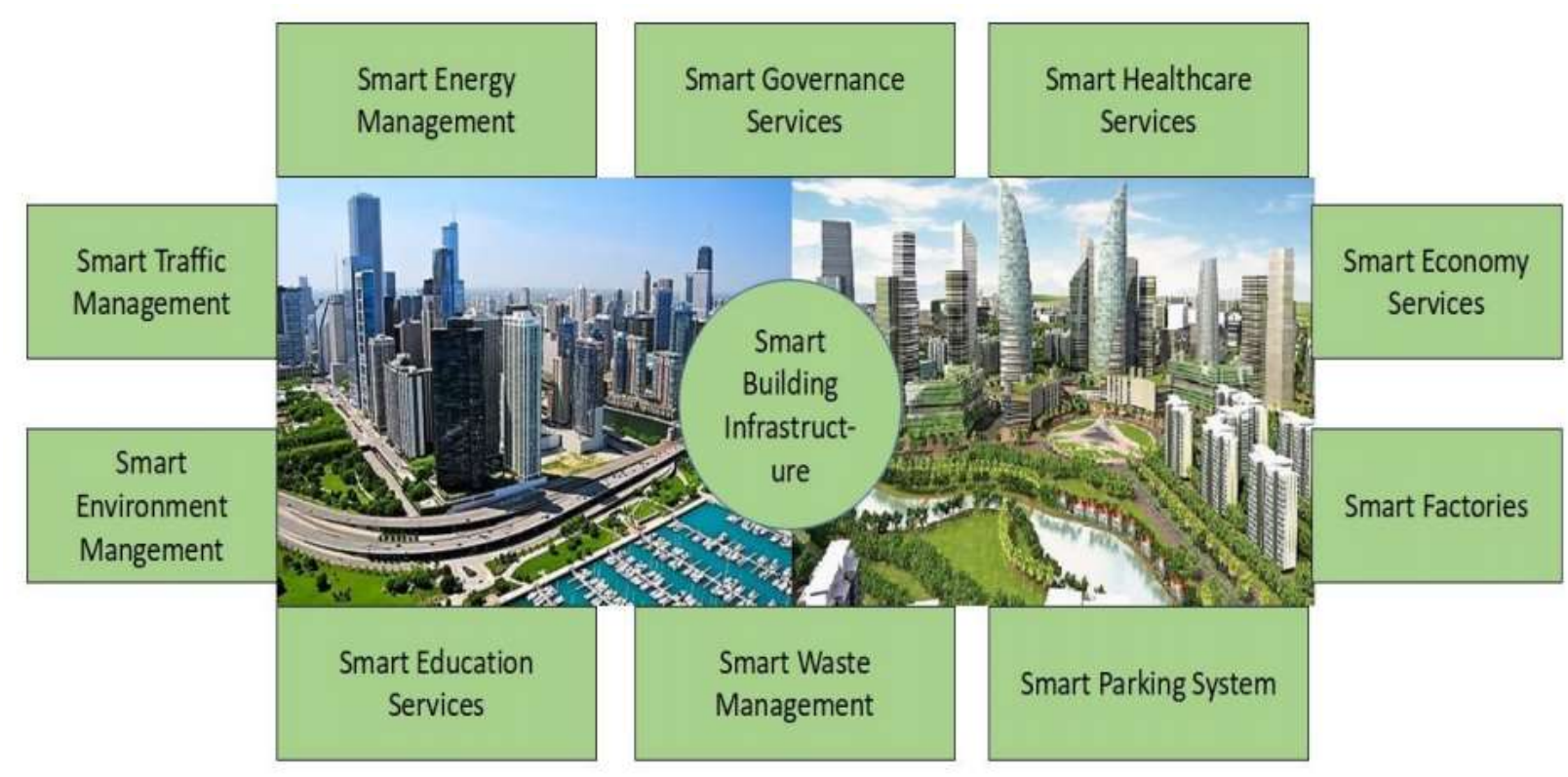

Fig. 1: Smart City typical Block Diagram [2]

\section{PROBLEM STATEMENT :}

Due to the need of an hour, during COVID-19 related pandemic situation across the globe, heavy investment is happening in uplifting the infrastructure and medical facilities. Since Smart Cities have played an influential role in curbing the deadly CORONA Virus, no doubt Smart Cities development is booming at an exponential rate. Many new technologies are extensively researched, explored, and effectively implemented in solving the real-life problems faced while setting up new Smart Cities and development of existing Smart Cities. While doing so, it is now becoming extremely important to maintain the records and information of all relevant future technologies and their applications in Smart Cities set up, development and evolution so that it can become a ready reference for the industry professionals and researchers working in this field. Unfortunately, there is not much readily available literature to meet this purpose. Through this research paper, an attempt is made to consolidate and present the information about selected future technologies which are extensively used in Smart City development, operation, and maintenance services. 


\section{RESEARCH OBJECTIVES :}

This Research Paper has covered information of selected future technologies based on their popularity, effectiveness, and adaptiveness in implementing with Smart City Services. Keeping in mind the scope, availability of literature, and time constraints, the paper is having the following broad research objectives:

- Exploration of future technologies applications in setting up and development of Smart Cities

- Identify implementation challenges of such future technologies and their ready adaptability in Smart City Services

- Provide details on selected future technologies and how they are getting utilized in Smart City Services

- Identify future technology trends in the development, Operation, and maintenance of Smart Cities

\section{METHODOLOGY :}

While preparing this research paper, multiple techniques were used to collect the facts and findings. The key methods used are a systematic review of existing research papers, interactions with industry experts, SMEs, and Researchers with a predefined set of questionnaires and finally analysis of the collected information with the set of defined criteria, techniques, and correlation algorithms to identify the most important and the latest technologies which are playing an influential role in Smart Cities development and operations. While collecting the existing literature, the focus was on the literature available in Scopus, Web of Science, UGC approved, and high impact factor reputed national and international research journals. I also relied on the data available on dedicated websites devoted to the given research area and information online published by technical experts and consultants. Various keywords such as "Future Technologies", "Latest Technologies" "Smart City Technologies", "Technology Trends" etc. were used in combination with keywords "Smart City" and "Smart Cities" to identify relevant research papers. Multiple rounds of interactions with known SMEs, Industry experts, and researchers working in Smart City domains were carried out via telephone interviews, Online web Meetings, and emails specifically by asking questions with respect to the latest technologies being employed in solving real-life challenges in Smart City Services, proposed technologies while setting up new Smart Cities, maximum budget allocation for which of the latest technologies and tools, etc. The collected data was then further analysed using criteria such as:

- Latest technologies that have received recommendations from the maximum number of stakeholders

- Maximum number of Research papers that have consistently covered information about most sought-after technologies with reference to Smart Cities

- Highest allocated budget for which latest technologies

- Maximum number of Proof of Concepts (POCs) and Minimum Viable Products (MVPs) using selected latest technologies for solving real-life challenges faced by Smart City services

- Data correlation on number of data parameters such as money saved, time taken to implement the solution, procurement expenses, deployment data, number of Smart Cities using the Solutions, etc. from quantified information collected so far.

\section{LITERATURE SURVEY :}

Smart Cities are playing an influential role in facilitating better medical services and a comfortable lifestyle to their citizens, this is witnessed prominently during Covid-19 period and no doubt across the globe, living in Smart Cities is much appreciated by everyone. As per United Nations, $68 \%$ of the world's population will be living in urban cities by the year 2050 and the world is also projected to have 43 megacities with more than 10 million inhabitants by 2030. As the Smart Cities population grows, it starts creating stress on Smart City services due to its limited resources and infrastructure such as transportation facilities, Medical Services, Smart Buildings, Electricity, Water, and so on. As pointed out by Laura-Diana Radu in her research paper "Disruptive Technologies in Smart Cities: A Survey on Current Trends and Challenges" [3], to tackle real-life issues and challenges faced by Smart Cities, well ahead of time, Smart Cities often makes an investment, undertakes research, and promotes the use of latest tools and technologies. The author also concluded that the latest technologies such as IoT, Big 
Data, Blockchain, AI and ML are the most significant disruptive technologies responsible for the evolution of Smart Cities and these are the latest emerging fields of research and practice in the context of Smart Cities. New tools and technologies in most cases often allow a quick resolution and effective turnaround to some of the pain problems which could not be solved by the conventional tools/technologies.

Nina Cvar and et al. in their research paper "The Use of IoT Technology in Smart Cities and Smart Villages: Similarities, Differences, and Future Prospects" [4] have clarified that the Internet of Things (IoT) is the latest technology which is equally effective for Smart Cities and Smart Villages. Authors claimed that IoT can be used to solve issues pertaining to monitoring and management of natural resources and energy, Smart Buildings, Transport and Mobility, Governance, and administration activities for Smart Cities and Smart Villages. Authors believed that the issues faced while managing Smart Cities and Smart Villages are more or less the same and the use of IoT technology can be found very effective and empowering the overall quality of life of their residents. Similarly, Andrea Zanella, et al. in their research paper "Internet of Things for Smart Cities" [5], have also stressed using IoT in Smart Cities to effectively implement various digital services of Smart Cities. Authors in their paper analysed the solutions presently available for the implementation of urban IoTs. They also clarified that IoT technology is a bit complex due to the involvement of a variety of sensors, services, and link-layer technologies and aims at exploiting the most advanced communication technologies to support valueadded services for the administration of the Smart City.

Leonardo Guevara and Fernando Cheein in their paper "The Role of 5G Technologies: Challenges in Smart Cities and Intelligent Transportation Systems" [6] have clarified that the 4G technology is replaced by new $5 \mathrm{G}$ technology to overcome the flaws in communication by $4 \mathrm{G}$. Authors claimed that the new 5G Technology in Smart Cities can be very effective in intelligent transportation systems and can be fully integrated by allowing ubiquity of network and massive simultaneous connections even under densely populated areas with high mobility situations. Authors believe that the 5G Technology can be a key enabler for the Internet of Things and its corresponding vehicular internet network. The authors provided detailed information on how 5G technology can impact Smart Cities intelligent transportation systems consisting of semi-autonomous and fully autonomous vehicles and respective vehicular communication. Dr. Smys, Dr. Wang, and Dr. Abul Basar in their paper "5G Network Simulation in Smart Cities using Neural Network Algorithm" [7] discussed details of their implementation of random neural networks in 5G and IoT for smart cities. Authors have clarified that $5 \mathrm{G}$ is going to replace $4 \mathrm{G}$ and will be bringing a revolution in the video and data communication field. $5 \mathrm{G}$ is more powerful and will be used provide internet services using Big Data to reduce the requirement of mobile networks and will also find extensive uses in IoT-powered Smart City Services. Authors have also highlighted the importance of cybersecurity while receiving and transmitting data over the Internet. To address cyber security-related threats authors proposed a solution based on random neural network blockchain technology which can effectively provide cybersecurity in many applications.

In most cases, technology implementation and deployment in Smart City services can improve the service quality dramatically but may not help to predict and resolve the problems well in advance. Many researchers and industry stakeholders have stressed the importance of better diagnostics capabilities with Smart City services. The main reason is the complex nature of Smart City Services architecture and their impact on the life of city residents and stakeholders in case of failure of any Smart City Service. Digital Twins is one of the effective technology solutions to deal with such problems. Digital Twins are available for Industrial Systems, but many people are not aware that Digital Twins can be utilized to simulate and model the existing Smart City as well. Nowadays, some of the Smart Cities are set up using Digital Twin Technology to better understand and serve the Smart City purpose. Amravati is one of the Smart Cities in Andhra Pradesh in India which has been set up and maintained using Digital Twin Technology. Fabin Dembski, et al, have discussed in detail in their paper "Urban Digital Twins for Smart Cities and Citizens: The Case Study of Herrenberg, Germany" [8] about the prototype of an urban digital twin for the 30,000-people town of Herrenberg in Germany. In this paper, the authors provided detailed information about their Digital Twin Prototype which was implemented using a visualization platform for virtual reality and has comprised of 3D Model of the City, Network street model of the city based on theory and space syntax, simulation of urban mobility, people's movement patterns, city wind flow simulation and the collective analysis of geographical data of the city. Authors claimed that the Digital Twin Model of Herrenberg City was found very useful and interesting as well as simple and 
entertaining as well by the stakeholders who participated in evaluating the Digital Twin Model. In a similar way, David Ford et al. in their paper "Smart Cities with Digital Twin Systems for Disaster Management" [9] successfully presented how Digital Twin Model can be effectively used for Smart City Disaster Management. The authors also highlighted the importance that developing the Digital Twin of any Smart City requires sensing and simulation capability across Smart City Infrastructure. Smart City residents during the Covid-19 pandemic started making online transactions heavily but at the same time, contactless transactions also became very popular in day-to-day activities while doing physical purchases at various shops and merchant stores, and showrooms. Gonzalo García, Irene Ruiz, and Miguel Ángel in their paper "State of the Art, Trends and Future of Bluetooth Low Energy, Near Field Communication and Visible Light Communication in the Development of Smart Cities" [10], have discussed in detail various mechanisms for facilitating Contactless technologies such as Bluetooth Low Energy (BLE), Visible Light Communication (VLC), Near Field Communication (NFC) and their use and influence within different areas of the development of the smart city. Contactless technologies can be effectively combined with IoT and Big Data-based Applications in Smart Cities. Arunmozhi Manimuthu, et al in their paper "Contactless Technologies for Smart Cities: Big Data, IoT, and Cloud Infrastructures" [11] have discussed in detail technology standards, applications, cost-effective techniques, and design principles that leverage Big Data, IoT, and Cloud Infrastructure for contactless applications and their user interfaces deployed in smart city environments.

As we are aware of that Smart City Services, mostly rely on their digital infrastructure to carry out almost all the transactions online. While making such online transactions, considering recent cyber security frauds, it is almost important that the city residents and various stakeholders should be able to carry on safe and secure transactions without any worry. To address this requirement now a day various Smart Cities have started adopting Blockchain Technology based services that allows all the online transactions between its users and service providers without having any need of third-party intermediaries for Transaction authorisation, making it fully secure and reliable. Christian Nãsulea and Stelian-Mihai Mic in their paper "Using Blockchain as a Platform for Smart Cities" [12] have proposed Smart City Model based on Blockchain Technology. The Authors highlighted having Blockchain Technology based services for Smart Cities and claimed Blockchain Technology as a disruptive technology which is powerful enough in shaping smart communities of the future that are more efficient and can have a better quality of living. Dipak Gade and P.S. Aithal in their paper "Blockchain Technology: A Driving Force in Smart Cities Development" [13] explained Blockchain Technology basics in details and also discussed in detailed how various Services of Smart Cities such as Smart Governance and Identity Management, Health Records, Energy Trading Solutions, Insurance, Supply Chain Management are getting benefitted by adopting Blockchain Technology based secure layer in their architecture. Carmen R., Alexandru G., et al. in their paper "Smart City Ecosystem Using Blockchain Technology" [14] described in detail various applications of Blockchain Technology within Smart City and proposed a Smart City ecosystem model based on authentication using Self-Sovereign Identity (SSI) model and Smart Contracts among administration authorities, citizens and various entities. They also overview the domains in which this technology can be used.

In Smart Cities, to continuously improve the experience and living life of its residents, services are becoming smarter day by day, thanks to Artificial Intelligence and Machine Learning Technologies. Juan M. Corchado, in the paper "Efficiency and Reliability in Bringing AI into Transport and Smart Cities Solutions" [15] have expressed that, the demand for more intelligence, fast speed, growing processing power, and the low cost of cloud infrastructure has made it possible the development of efficient and powerful algorithms. With the processing power of these algorithms in Data Analytics, Big Data Processing, Convolutional Networks, and Deep Learning are transforming the way we operate and work. Authors argued that the combination of technologies such as Blockchain with Artificial Intelligence along with IoT is very powerful and can offer a lot of opportunities and a world of possibilities across Smart Cities. Himanshu Sharma, Ahteshamul Haque, and Frede Blaabjerg in their review paper "Machine Learning in Wireless Sensor Networks for Smart Cities: A Survey" [16] discussed in detail the ML Techniques survey in WSN IoT for various services of Smart Cities and the challenges they faced. Authors have claimed that Machine Learning and Artificial Intelligence can efficiently manage and automate the operation of IoT nodes deployed across Smart City. With their survey, they concluded that $61 \%$ of Smart City Applications have used ML supervised learning algorithms in their architecture and design, whereas $12 \%$ of applications have used unsupervised 
learning techniques and 27\% of the Smart City applications have used reinforcement learning. Whereas Maitreyee Dey, Soumya Rana, and Sandra Dudley, in their research paper "A Case Study Based Approach for Remote Fault Detection Using Multi-level Machine Learning in a Smart Building" [17] have discussed how a multi-level machine learning technique can be used for remote fault detection in smart buildings. Smart Buildings are an integral part of Smart Cities. The authors concluded that a multi-level machine learning framework was found very effective in automatic fault detection in smart buildings. They also claimed that predictive machine learning methods can be very useful in creating Smart Buildings with a facility of automatic fault finding in heating and cooling systems of such buildings.

\section{SMART CITY OBJECTIVES :}

There can be various purposes behind setting up Smart Cities, however, the key objectives which supposed to be met by any Smart City are as follows.

(1) Efficient and Smart Services: Provide high-quality and efficient services using optimized public resources. The Services can be adequate Water Supply, assured Electricity, Smart Housing, Media and Entertainment Services, Solid Waste Management and Sanitation, etc.

(2) Safety and Security: This relates to not only the physical safety and security of Smart City residents but also includes their data security.

(3) Disaster Management: Protection of physical and digital assets of Smart City residents in case of natural calamities and or emergency situations

(4) Smart Mobility - To offer safe, cost-effective, and efficient transportation (using footpaths, dedicated bicycle paths, public transportation, Goods Carrier, etc.) for smart city residents as well as for physical goods with the least delay and time wastage

(5) Financial growth - To attract, retain and protect the financial interest of various stakeholders including citizens, businessmen, retailors, Investors, and visitors.

(6) Sustainability: Develop, grow, and sustain the Smart City with a strong consideration of green environmental policies.

(7) Reputation: Maintain and consistently improve the reputation and image of Smart City.

Note that the effectiveness and ranking of any Smart City can be very well judged based on how effectively the key objectives are met by the Smart City [18]. In addition to the key objectives, the Smart City may have multiple secondary objectives based on the expectations from its stakeholders.

\section{KEY TECHNOLOGIES IN SMART CITIES :}

We are now aware of that the framework of Smart Cities is based on the latest technologies and tools and evolving on a continuous basis. Most of the time while carrying out its operations and services, Smart Cities relies heavily upon IoT sensors that are connected or networked together, and the processing of a large amount of data that originates from various sensors [19]. Because of such activities, Smart Cities are often called Wired Cities or Digital Cities or Sensor Cities, or even Intelligent Cities sometimes. Smart cities are playing a very critical role in the development and overall growth of urban areas, regions, and thus overall country and hence Smart Cities development is always given high priority while setting up a financial budget. Due to enough funding and support from the public and private organizations, Smart Cities in their transformational journey, from last few years, have actively started using some advanced technologies such as Blockchain, 5G, Digital Twins, etc. Let us explore some of these new technologies that are playing a very critical role in Smart Cities development and operations [20-32].

(1) Blockchain Technology

(2) Digital Twins

(3) $5 \mathrm{G}$

(4) Contactless Technology

(5) Artificial Intelligence (AI) and Machine Learning (ML)

(6) Internet of Things (IoT) 


\section{(1) Blockchain Technology}

Blockchain Technology has gain wide popularity over few years not only for offering Cryptocurrencies but also as a solid secure technology-based framework that can be used to secure any online transactions that need a secure and robust cybersecurity compliance platform. Blockchain Technology facilitates connecting different services to track data, arrest security breaches if any, assure transparency, removing of any third-party dependency, and provide seamless transactions. A Blockchain in simplicity is a chain of blocks where each block contains transaction data in an encrypted fashion and a hash of previous Block Contents. This chain of blocks gets added a new block to record the new data transactions. These data blocks are stored in a distributed database and can be accessible by authenticated users only. In summary, Blockchain offers an encrypted distributed secure database that is operated in a decentralized manner and extremely reliable in operation. Blockchain Technology facilitates communications between stakeholders and facility providers in distributed manner without need of any intermediate or a central authority. Transactions are authorised and executed through Smart Contracts seamlessly and securely. Refer the figure 2 which has presented the Smart City model based on Blockchain Technology. The record in Blockchain once created, cannot be altered at any stage. The data records when need modifications, can be appended only with the new data records, thus modification history always remains available for any audit or data inspection. Blockchain digital data record is safe and minimizes any third-party involvement while creating the digital record. Since Smart Cities heavily uses and relying upon online data transactions, data security and transparency are mainly key criteria while executing such services for any Smart City, since Blockchain Technology offers a secure robust platform for such kind of online transactions, Blockchain Technology-enabled services are rapidly becoming popular in Smart Cities development, operations, and maintenance.

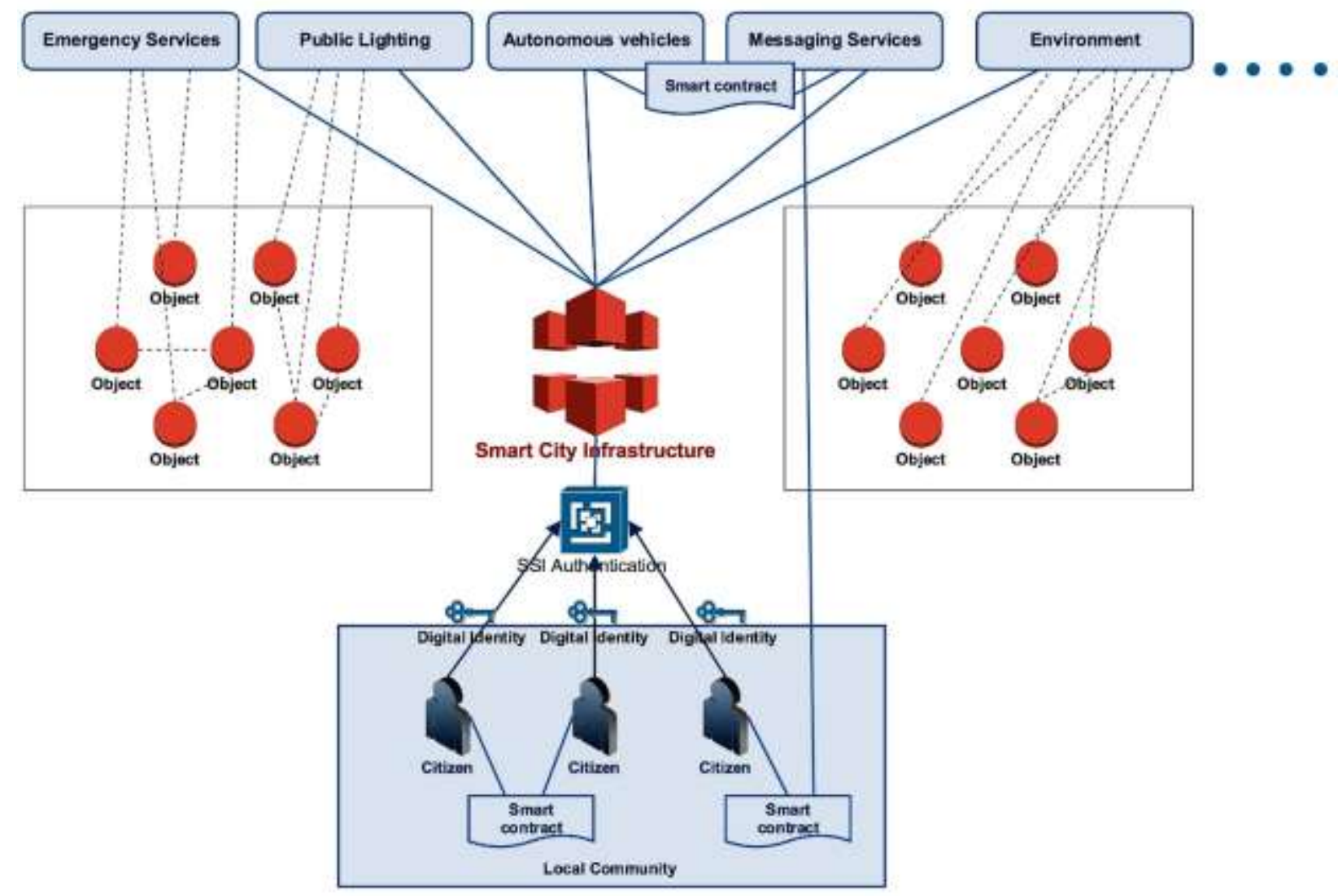

Fig. 2: Smart City Model based on Blockchain Technology [14]

Some of the operational areas and selected services from Smart Cities that actively using Blockchain Technology are as follows.

- Supply Chain Management 
- Insurance Services

- Patients Medical Records

- City Administration and Governance Service

- Energy Trading Solutions

- Identification Management

- Online Financial Transactions

- Smart Contracts

\section{(2) Digital Twins}

Digital Twin is referred to a virtual or digital model. The virtual or digital model mostly exhibits the same behaviour as the original system when exposed to simulated real-life situations. This helps in studying, analysis and predicting the impact of certain situations and conditions on real things much ahead of time by exposing the same situations and conditions with its digital twin. Digital Twin of Smart City is a complete virtual replica or digital model of the Smart City - a simulated model, simulating its building infrastructure, IT services, roads, transportation facilities, ICT infrastructure, public spaces, and entertainment areas, combined with real-time data feeds collected from real sensors. With the help of Digital Twin, Smart City stakeholders can visualize the emergency situation impact, analyse the disaster management scenarios, plan rescue operations, respond to changes in the environment, the effect of changes in layouts, and similar, such things which are hard to visualize or analyse well ahead of time. Modern infrastructure and advancements in various technologies such as IoT, Augmented and Virtual Reality, Machine Learning, and Artificial Intelligence have made it possible to create the digital model of any objects from the real physical world. Digital Twin is capable of behaving in the same manner as the real thing when exposed to real-time data as inputs. Refer to figure 3, which has presented a virtual model of Smart City i.e., Digital Twin of Smart City, which is simulated and presented on PC. By analysing the behaviour of Digital Twin, it is possible to have better decision making, predict maintenance issues, and reduce downtime of any critical infrastructure equipment. Digital Twins are also popular in other domains such as manufacturing sectors, industries, Aerospace, etc. As per the 2018 GE report, it is stated that GE has almost 1.2 million Digital Twins for its various assets in order to maintain them properly and to identify any breakdown issues well ahead of time. Considering various advantages offered by Digital Twins, various Smart Cities across the globe have started building their Digital Twins in order to better maintain and upkeep its operations. Singapore is already building a virtual Singapore project where a 3-dimensional digital City model is being created with an intention to be used as a testbed by the city administration authorities and all the stakeholders. This model shall allow the builders, city layout engineers, planners to decide the best location and route layout and infrastructure deployment, before actually building it to understand how it will work and improve the Smart City. This is done with the intention to build a more resilient city.

In India too, a new capital of Andhra Pradesh i.e., Amaravati, is being set up using Digital Twin. The Digital Twin is going to help the government officials to evaluate the construction plan, monitor and manage the city resources and plans well ahead of time. Digital Twins are now so popular that stakeholders are now planning to create a network of Digital Twins so that the resources can be collaborated and can be used more effectively across geographies. The Association of Southeast Asian Nations has established a pilot project to build such a network of Digital Twins of Smart Cities.

\section{(3) $5 G$}

5G is a fifth-generation digital cellular network, faster than $4 \mathrm{G}$ and has wider data bandwidth, and has much lower latency as compared to its predecessor's technologies. The 5G digital cellular network started deployment across the globe by 2019. 5G is the planned successor to the 4G networks which provide connectivity to most current cellphones around the world. According to GSM Association, the $5 \mathrm{G}$ network is predicted to have more than 1.7 billion worldwide subscribers by 2025 . As stated earlier, Smart Cities mostly rely on a massive amount of data generated from various IoT sensors deployed across the cities and this generated data needs to be analysed and processed by the various infrastructure elements which subsequently affects Smart City operations. Since 5G supports the fastest data transmission over a network, it is the most popular cellular network in Smart Cities nowadays since it effectively avoids data latency and transmits the data with the speed which is needed by most of the Smart Cities servers and nodes. In today's era, 5G is an enabling technology for IoT, and since Smart 
Cities essentially rely on IoT to function, $5 \mathrm{G}$ and Smart Cities are close inter-linked. The speed at which $5 \mathrm{G}$ is deployed across the globe will definitely have a significant impact on everything by having faster communications, higher bandwidth, and more reliability at lower costs and it is just a matter of time to become a defining technology of Smart Cities. Refer figure 4, which has presented the key elements of $5 \mathrm{G}$ Network. As shown in figure 4, Small cells are one of the key elements in 5G Network, and they provide the increased data capacity that $5 \mathrm{G}$ demands.

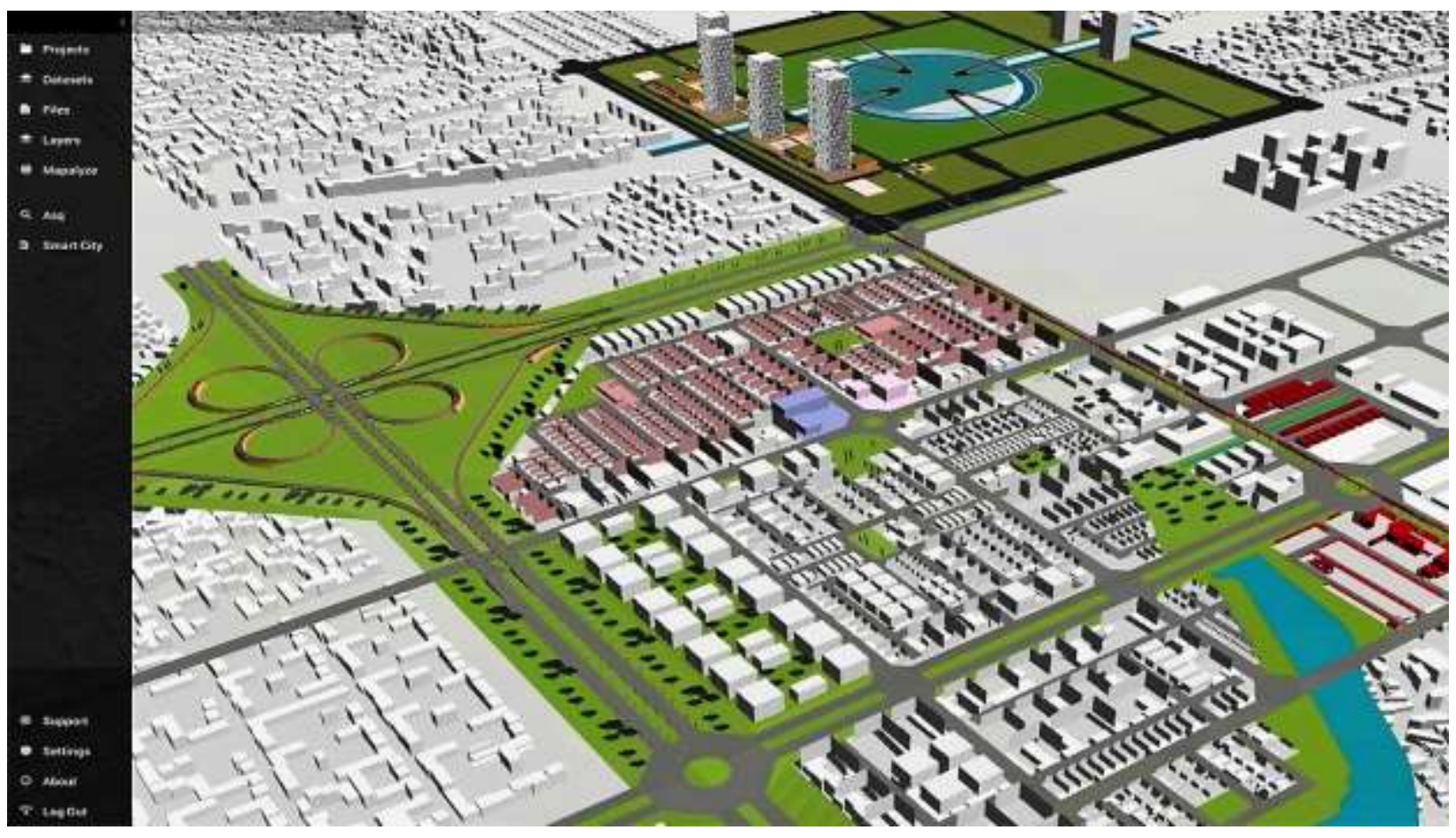

Fig. 3: Smart City Digital Twin Model [Source : SmartCitiesWorld.net]

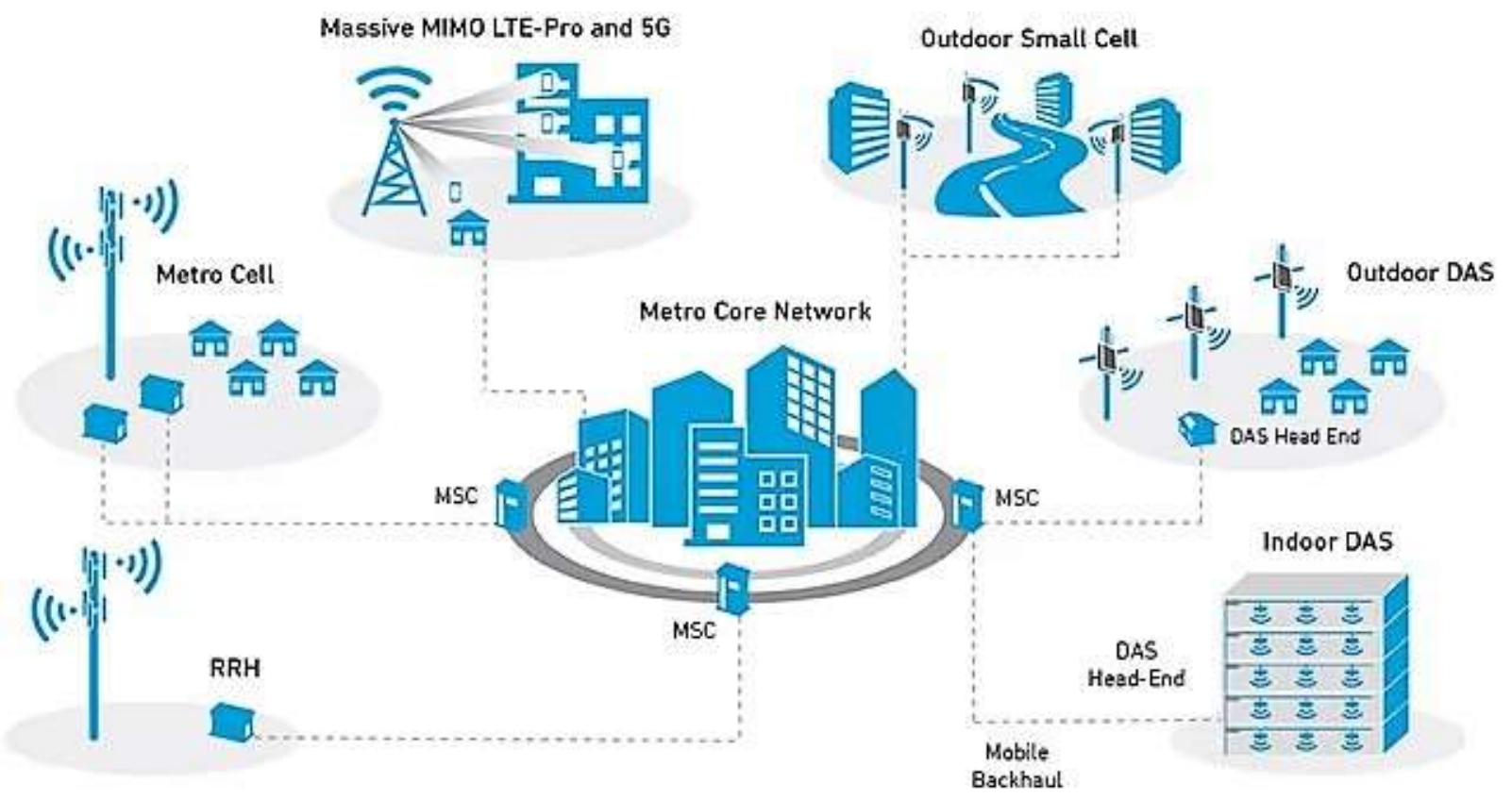

Fig. 4: Key elements of 5G Network [Source : Qorvo] 
Some of the selected most effective services in Smart Cities where 5G is playing an influential role are as follows

- Traffic Monitoring and Control: This requires high-speed transmission of real-time live footage of traffics data and videos for analysis and processing purposes where high bandwidth and fast data communication speed is an essential requirement. This is fulfilled effectively by $5 \mathrm{G}$.

- Public Safety and Security: This service needs to analyse and process real-time footage of security surveillance cameras where high bandwidth, faster processing, and communication are needed, which can be promised only by using $5 \mathrm{G}$ Technology.

- Media and Entertainment: This service needs very fast upload and download of large-size Videos and Music files to provide effective entertainment to its subscribers. Due to large bandwidth and faster communication, with the help of $5 \mathrm{G}$, it is possible now to get the best entertainment to users without any lag.

\section{(4) Contactless Technology}

Contactless technology enables transactions using near-field communication (NFC). Contactless technology as the name suggests is a contactless form of communication technology used for doing card-based transactions. With the help of Contactless technology, it is possible for users to do the smartcard-based payment by just putting the card near the Point of Sale (POS), this process doesn't need the user to enter the PIN for the transaction or to insert a card in POS machine. This technology relies on NFC which is basically a short-range wireless communication technology such as RFID which allows instant data communication among devices that are several centimetres apart. RFID-based smart cards are also extensively used as public transportation passes, for toll payments, and in security systems for door access control. In Smart Cities, Contactless Technology is extensively now used to authorize contactless payments instantly. In the Covid19 period, specifically, contactless payments were highly sought after and most recommended. In many Smart Cities, to curb the pandemic situation due to Covid19, many systems were upgraded to use contactless technologies wherever applicable. Today this technology is highly popular not only in Smart Cities but everywhere and it is estimated that almost $60 \%$ of payment transactions are conducted via contactless technology.

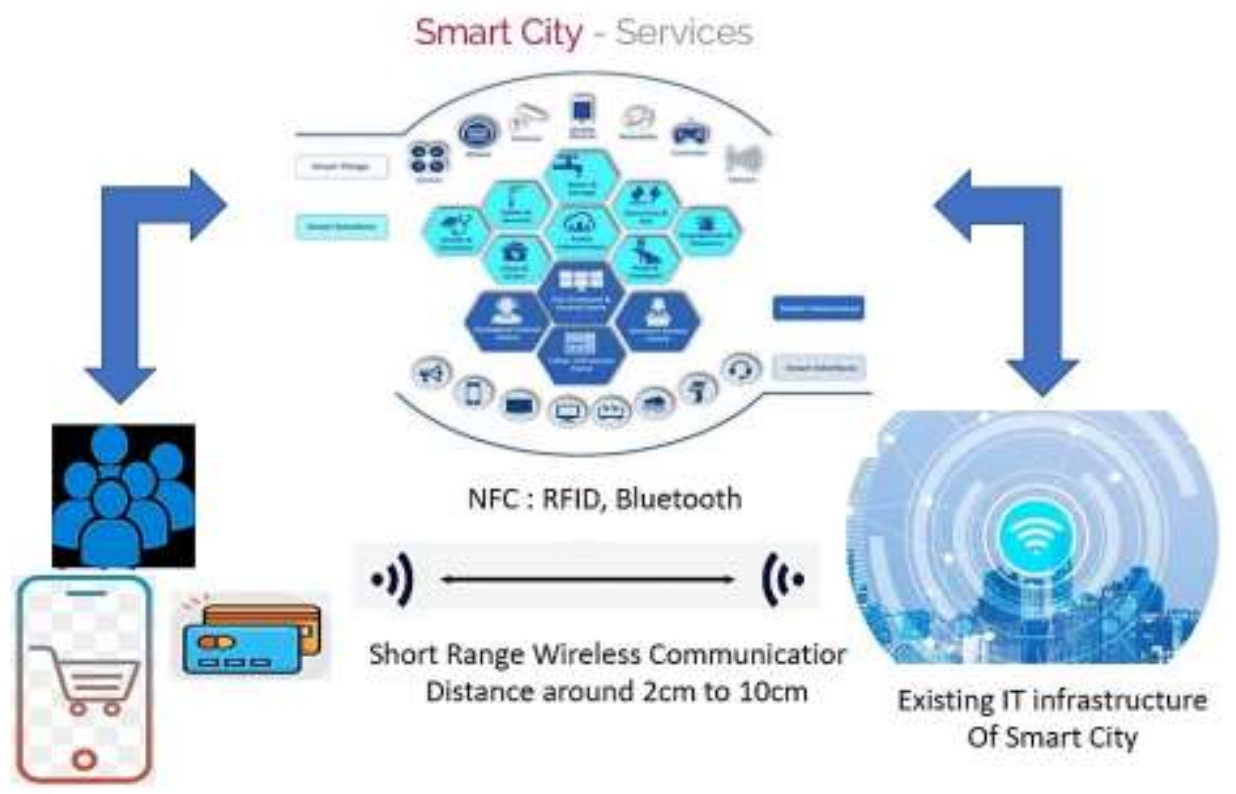

Fig. 5: Smart City Contactless Technology Typical Setup [18]

Refer to figure 5 above which has presented a typical system of Smart City which is based on Contactless Technology. As shown in the block diagram, the existing IT infrastructure of Smart City, very well can be used with Smart Card based transactions using near field communication devices. Because of convenience, faster and secure operation, these transactions are very popular among Smart City stakeholders. In Smart City, some of the services which use Contactless Technology extensively are as follows. 
- Door Access Control in Secured Offices and establishments, residential complex and Hotels

- Public Transportation Pass (Buses, Trains, and shared transports)

- Vehicle Toll Gate Pass for automatic toll gate payment

- Retail consumer payment transactions in Malls, Super Marts and Shopping Complex

- Education Institution Students Pass for accessing Libraries, Labs, Servers, etc.

\section{(5) Artificial Intelligence (AI) and Machine Learning (ML)}

Artificial Intelligence is the programmatically built intelligence in the system which offers the capability to the system to think and analyse the situation before taking any action. Machine Learning offers the capability to the system to learn from the present and past inputs and situations. ML with the help of various algorithms analyses the data generated from various sources and tries to identify the pattern out of it and based on the data correlation, learn how to optimize the given set of services. Most of the time AI and ML go hand in hand and offer the best advantages to each other. ML helps AI to perform better over a period of time by offering better learning capability and do wonders with the software systems and that is the reason AI and ML algorithms have increasingly become an integral part of industrial automation and various domains. No doubt, AI and ML have already proved their importance and paved their way in the Smart Cities development journey to automate and advance various services, activities, and operations at large and are able to personalize the smart city experience by aggregating information. AI and ML have the ability to understand how Smart Cities function and hence many Smart Cities programs using AI and ML have accelerated Smart City services and their automation and thereby offering an excellent experience to its stakeholders. By leveraging AI and ML capabilities along with IoT, Smart City can do better analysis on various real-life problems and can take accurate decisions, and even sometimes can predict issues well ahead of time. Be it Smart Traffic Control, Public Safety and Security, occupation and health monitoring, surveillance systems everywhere AI and ML have assisted Smart City services to take predictive control and action. Some of the selected services which use AI and ML extensively are as follows.

- Waste Collection, recycling, and disposal: AI and ML algorithms assist in identifying proactively the waste generation and trends and thereby can very well optimize the waste collection process. Also based on types of waste, it can determine the waste recycling and disposal requirements and trends.

- Traffic Management: Based on the analysis of Peak hours, mob-like situations, monitoring accident kind situations, AI and ML can proactively trigger the traffic jam notifications and can assist in traffic diversion. Also, in case of accidents, by automating the Ambulance calling, it can also provide emergency medical service very effectively.

- Emergency management: With the help of AI-powered computer vision systems, it is possible to automatically monitor millions of elements of urban life in a chorus, including vehicles, human beings, animals, fires, water, accidents, disasters, and so on. This helps in taking the proactive decisions and controlling any emergency situation well in advance with better planning and facilities.

\section{(6) Internet of Things (IoT)}

Internet of Things commonly known as IoT and in a broader sense as per ITU (International Telecommunication Union), IoT can be used to describe any object connected to the internet and network of such objects which can communicate with each other over the Internet. IoT technology is proven as blessings for Smart City applications, and it facilitates the capability of remote monitoring, communication, managing, and controlling the devices using sensors and generates real-time data which can be collected and further processed for useful analysis. In fact, many Smart Services of Smart Cities can become smarter using IoT Sensors (such as RFID, GPS, CCTV Cameras, Laser scanners, Temperature and Humidity, motion detector, etc.) and can assist the stakeholders the remote facilities (such as location tracking, image recognition, controlling of the devices, smart login, identifications, monitoring and managing the control devices remotely, etc.) at their convenience by using and processing the data generated through IoT Sensors. With the help of IoT sensors deployment, Smart City can become more interconnected, instrumental, and intelligent. Using IoT with the help of 
connected technologies and smart data analytics can create smart solutions, such solutions can easily solve real-life problems more effectively and can positively impact the quality of life of city residents and can help to lower the consumption of resources to a reasonable extent. It is obvious that the Smart City to function at its full potential IoT is becoming a vital ingredient.

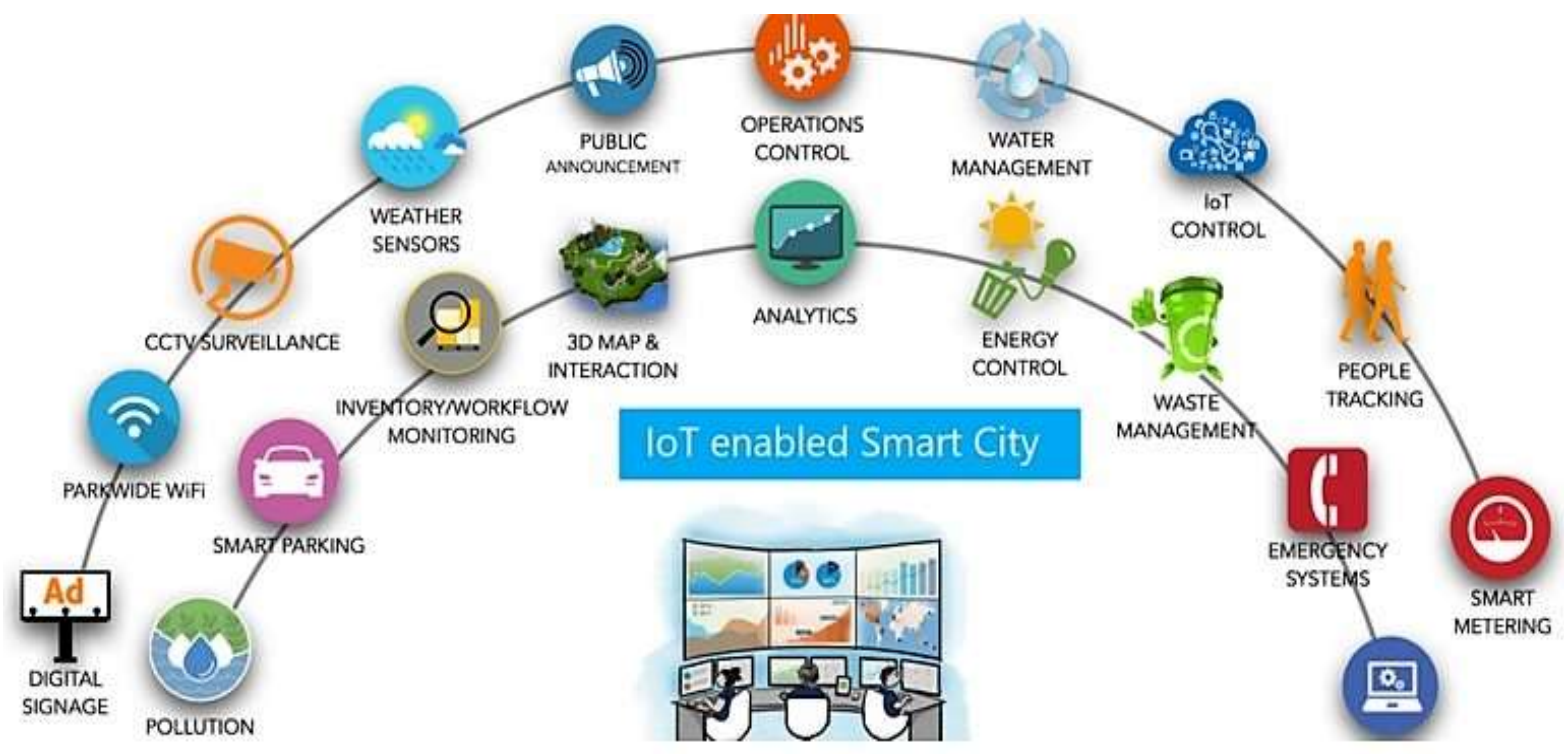

Fig. 6: IoT enabled Smart City [ Source: medium.com/tech-lounge]

Refer figure 6, which has presented the Smart City model based on IoT Technology. Note that IoT Sensors are extensively used in various services of Smart Cities and also it is possible to have various services of Smart City interlinked with each other over Internet and can use and share the data generated from IoT sensors for smart operation and maintenance activities of Smart Cities. IoT technology is effectively implemented in some of the following smart services of Smart Cities.

- Connected Streetlights

- Connected Public Transport

- Water Level / Flood Monitoring

- Traffic Monitoring and Management

- Video Surveillance and Analytics

- Weather Monitoring

- Smart Metering

- Air Quality / Pollution Monitoring

- Water Quality Monitoring

- Fire / Smoke Detection

- Water Quality Monitoring

8. STATISTICS WITH RESPECT TO KEY TECHNOLOGIES, REVENUES, AND INVESTMENTS :

We have already understood some of the key technologies which are playing a significant role in Smart Cities development and operations. Let us now check the interesting statistics about Smart Cities in connection with the key technologies employed, expected revenue earn and investments. Kindly note that these statistics are reported in "Statista and IDC FutureScape: Worldwide Smart Cities and Communities 2019 Predictions".

- Water Scarcity is considered as biggest risk Smart City has to deal with and hence it is expected that by the year 2024, around $45 \%$ of cities and communities will use IoT-enabled water management systems for monitoring usage, quality, and leakage detection.

- By 2022, Smart City investment is expected to peak to $\$ 158$ Billion where the most spending is expected in the transport sector along with fixed visual surveillance. 
- It is expected to enhance smart energy's share of the global Smart City market and is expected at $15.8 \%$.

- The global Smart City spending is expected to reach around $\$ 34.5$ billion by 2021 .

- The Smart City investment is expected to peak at $\$ 158$ Billion by 2022

- For 2021, revenue for smart lighting in the global residential building segment is expected to reach $\$ 2.88$ billion.

- For Medical services, Telehealth and Virtual Health service are expected to become key technology trends over the coming period of time.

- Smart home market around the world in 2021 is expected to be around $\$ 40.9$ billion.

- Smart construction and manufacturing sector is also expected to grow where revenue for commercial and institutional systems worldwide is expected to reach around $\$ 14.92$ million.

From the above statistics, it is clear that Smart Cities are heavily relying on various latest technologies such 5G, Blockchain, Digital Twin, AI, and ML, Contactless Technologies, Data Analytics, etc., and global countries are equipping Smart Cities by spending money to invest in latest technologies, tools, and Infrastructure.

\section{RESULTS AND DISCUSSION :}

In this paper, I have analysed, identified, reviewed, and discussed multiple technologies which basically playing an active role in the development, operation, and maintenance of Smart Cities. It is found that there are multiple tools, technologies, communication protocols, and IT infrastructure is used in Smart City services to deal with real-life challenges and issues while operating and maintaining Smart Cities. However, certain technologies definitely found very effective, efficient, and faster to deal with certain pain point issues Smart Cities are facing for a long and are unable to deal with them using conventional tools and technologies. The list of such disruptive technologies as stated in Table 1 below.

Table 1 : Summary of Key Technologies in Smart Cities

\begin{tabular}{|c|c|c|}
\hline Sr. No & Key Technologies & Key Applications/Services \\
\hline 1 & Internet of Things (IoT) & $\begin{array}{ll}\text { - } & \text { Connected Streetlights } \\
\text { - } & \text { Traffic Monitoring and Management } \\
\text { - } & \text { Water Level / Flood monitoring } \\
\text { - } & \text { Video surveillance and Analytics } \\
\text { - } & \text { Weather Monitoring } \\
\text { - } & \text { Smart Metering } \\
\text { - } & \text { Air Quality / Pollution Monitoring } \\
\text { - } & \text { Fire / Smoke Detection }\end{array}$ \\
\hline 2 & Blockchain & $\begin{array}{l}\text { - Supply Chain Management } \\
\text { - Insurance Services } \\
\text { - Smart Medical Records } \\
\text { - Smart City Governance } \\
\text { - Energy Trading Solutions } \\
\text { - Identification Management } \\
\end{array}$ \\
\hline 3 & $5 \mathrm{G}$ & $\begin{array}{l}\text { - } \quad \text { Traffic Monitoring and Management } \\
\text { - } \quad \text { Security Surveillance } \\
\text { - } \quad \text { Media and Entertainment } \\
\text { - } \quad \text { Vehicular Intercommunication Network }\end{array}$ \\
\hline 4 & Artificial Intelligence (AI) & $\begin{array}{l}\text { - } \text { Waste Management } \\
\text { - } \quad \text { Traffic Monitoring and Management } \\
\text { - Smart Communications } \\
\text { - } \quad \text { Autonomous Vehicles }\end{array}$ \\
\hline 5 & Machine Learning (ML) & $\begin{array}{ll}\text { - } & \text { Disaster Management } \\
\text { - } & \text { Smart Communications } \\
\text { - } & \text { Predictive Diagnostics } \\
\end{array}$ \\
\hline
\end{tabular}




\begin{tabular}{|c|l|l|}
\hline $\mathbf{6}$ & Contactless Technology & $\begin{array}{l}\text { - Door Access Control } \\
\text { - }\end{array}$ \\
& & $\begin{array}{l}\text { - } \\
\text { - Automat Payment }\end{array}$ \\
& & - Public Transportation Pass \\
& & - Automatic Fare Collection \\
\hline $\mathbf{7}$ & Digital Twins & Disaster Management \\
& & - Capacity Management \\
& & Load and Power Management \\
\hline
\end{tabular}

Based on the detailed study and analysis of these technologies, it is also found that

- Technologies such as IoT, AI, ML, Blockchain, Digital Twin, Contactless Technology and 5G are the most significant disruptive technologies for the evolution of Smart Cities

- These key technologies are very powerful and can bring huge positive changes in Smart Cities if utilised with proper control and responsibility

- The identified key technologies are interdependent and often used together to get the best advantage

- These key technologies are invented recently, almost in the same time period, and are expected to evolve together

\section{CONCLUSION :}

Smart Cities are growing at a very fast rate and worldwide countries are heavily investing in the development of Smart Cities. The reason is very obvious, the developed countries, as well as developing countries, are aware of the importance of Smart Cities and the way Smart Cities are making an impact on urban living. Specifically, before and during the Covid-19 period, Smart Cities could tackle the medical emergency situation very effectively due to its various smart services such as Smart Transportation, Smart Medical Assistance, Smart Patient Care, Electronic Medical Record, Smart Emergency Management, and so on. Smart Cities can offer better services to their residents only because of the latest technology-based infrastructure and tools. So many new technologies are employed while implementing various Smart Services of Smart Cities. In this paper, we have seen that how faster $5 \mathrm{G}$ wireless network is impacting networking among stakeholders and digital media and entertainment services. Also, the use of contactless technologies during shopping has changed the way stakeholders do the payment, this has proved very effective and the safe recommended practice specifically during Covid-19 situations. Blockchain Technology has also boosted the confidence of stakeholders in online financial transactions, which has automatically brought more transparency and a safer experience to users. It should also be noted that Smart City has a very complex infrastructure and needs regular maintenance and many times predictive maintenance just to ensure that Smart City services should not be interrupted at any stages. AI and ML also playing a game changer technology in Smart City operations by offering facilities like data analytics, failure analysis, intelligent dashboard, and various such functionalities which are gaining immense popularity. With Digital Twin technologies, it became possible for Smart Cities to effectively maintain their infrastructure and services to predict any failure well ahead of time.

\section{FUTURE WORK :}

In this research paper, we have identified some of the selected latest technologies which are found very effective in Smart City development and operations. The detailed information with respect to the number of application areas where these latest technologies are employed and effectively used, could not be covered due to restricted time and other constraints. Based on the useful data analysis and outcome of this paper, however, in the future, it is definitely worth exploring in detail how the selected technologies are used in Smart City Services and how they are impacting the Smart City development and operations activities. This will definitely help in identifying limitations if any with the latest technologies and possible solutions to solve them. I am planning to prepare separate research papers in the future covering this intended information with respect to each identified technology.

\section{REFERENCES :}


[1] Smart Cities Mission Statement \& Guidelines. (2015). Retrieved from http://smartcities.gov.in/ on August 01, 2021.

[2] Gade, Dipak S. (2019). Introduction to Smart Cities and Selected Literature Review. International Journal of Advance and Innovative Research, 6(2), 7-15.

[3] Laura-Diana Radu. (2020). Disruptive Technologies in Smart Cities: A Survey on Current Trends and Challenges. MDPI Journal, Smart Cities, 3(3), 1022-1038.

[4] Nina Cvar, Jure Trilar, Andrej Kos, Mojca Volk and Emilija Stojmenova Duh. (2020). The Use of IoT Technology in Smart Cities and Smart Villages: Similarities, Differences, and Future Prospects. MDPI Journal, Sensors, 20(3897), 1-20.

[5] Andrea Zanella, Nicola Bui, Angelo Castellani,Lorenzo Vangelista, and Michele Zorzi. (2014). Internet of Things for Smart Cities. IEEE Internet of Things Journal, 1(1), 22-32.

[6] Leonardo Guevara and Fernando Auat Cheein, (2020). The Role of 5G Technologies: Challenges in Smart Cities and Intelligent Transportation Systems. MDPI Journal, Sustainability, 12(6469), $1-15$.

[7] Smya S., Haoxiang Wang, Basar A. (2021). 5G Network Simulation in Smart Cities using Neural Network Algorithm. Journal of Artificial Intelligence and Capsule Networks, 3(1), 43-52.

[8] Fabian Dembski, Uwe Wössner, Mike Letzgus, Michael Ruddat and Claudia Yamu. Urban Digital Twins for Smart Cities and Citizens: The Case Study of Herrenberg, Germany. MDPI Journal, Sustainability, 12(2307), 1-17.

[9] David N. Ford, \& Charles M. Wolf. (2020). Smart Cities with Digital Twin Systems for Disaster Management. Journal of Management in Engineering, 36(4), 1-10.

[10] Gonzalo Cerruela García, Irene Luque Ruiz and Miguel Ángel Gómez-Nieto. (2016). State of the Art, Trends and Future of Bluetooth Low Energy, Near Field Communication and Visible Light Communication in the Development of Smart Cities. MDPI Journal, Sensors, 16(1968), 1-38.

[11] Arunmozhi Manimuthu, Venugopal Dharshini, Ioannis Zografopoulos, Charalambos Konstantinou. (2021). Contactless Technologies for Smart Cities: Big Data, IoT, and Cloud Infrastructures. SN Computer Science, A springer Nature Journal, 2(334), 1-24.

[12] Christian Nãsulea, \& Stelian-Mihai Mic. (2018). Using Blockchain as a Platform for Smart Cities. Journal of E - Technology, 9(2), 37-43.

[13] Gade, Dipak S., \& Aithal, P. S. (2020). Blockchain Technology: A Driving Force in Smart Cities Development. International Journal of Applied Engineering and Management Letters (IJAEML), 4(2), 237-252.

[14] Carmen R., Alexandru G., et al., (2019). Smart City Ecosystem Using Blockchain Technology. Informatica Economică, 23(4), 41-50.

[15] Juan M. Corchado. (2019). Efficiency and Reliability in Bringing AI into Transport and Smart Cities Solutions. Proceedings of International Conference on Transport and Smart Cities, 1-12. https://gredos.usal.es/bitstream/handle/10366/140501/BISITE_Efficiency.pdf?sequence=1\&isA llowed=y

[16] Himanshu Sharma, Ahteshamul Haque, and Frede Blaabjerg (2021). Machine Learning in Wireless Sensor Networks for Smart Cities: A Survey. Electronics, MDPI Journal, 10(1012), 122.

[17] Maitreyee Dey, Soumya Prakash Rana and Sandra Dudley (2020). A Case Study Based Approach for Remote Fault Detection Using Multi-Level Machine Learning in A Smart Building. MDPI Journal, Smart Cities, 3(1), 401-419.

[18] Gade, D. S. (2021). Disruptive Technologies and Trends in Development and Transformation of Smart Cities. Recent Trends in Engineering and Technology (87-97), New Delhi: Anvi Book and Publishers 
[19] Gade, Dipak S. (2019). Technology Trends and Digital Solutions for Smart Cities Development. International Journal of Advance and Innovative Research 6(1), 29-37.

[20] Gade, Dipak S., \& Aithal, P. S., (2021). Smart Cities Development During and Post COVID-19 Pandemic - A Predictive Analysis. International Journal of Management, Technology, and Social Sciences (IJMTS), 6(1), 189-202.

[21] Gade, Dipak. (2015). Latest Innovations in Networking and Communications Technologies. Proceedings of International Conference on Emergence of India as a Global Economy: Challenges and Opportunities, 8(1), 55-57. http://ncrdsims.edu.in/site/views/pdfs/researchconferences/research-conferences-2015.pdf

[22] Linchpin. (2021). Trends Transforming and Shaping Smart Cities in 2021. Retrieved from https://linchpinseo.com/trends-that-will-transform-smart-cities/ on 30/07/2021.

[23] Rodger Lea. (2017). Smart Cities: An Overview of the Technology Trends Driving Smart Cities. IEEE. 1-16. DOI: https://doi.org/10.13140/RG.2.2.15303.39840.

[24] Arnoud van Gemeren. (2020). Key technology trends in smart cities. Retrieved from http://www.smartcityhub.com on 30/07/2021.

[25] Mohammed Bouzidi, et al., (2020). Use of the IQRF Technology in Internet-of-Things-Based Smart Cities. IEEE Access. 56615-56629.

[26] Gade, D. S. (2019). Introduction to Smart Cities and selected Literature Review. International Journal of Advance and Innovative Research, 6(2), 7-15

[27] Karen Field, (2021). From sensors to smart cities, the biggest tech trends in 2021 and beyond. Retrieved from http://www.fierceelectronics.com on 30/07/2021.

[28] Bernard Marr, (2020). The Smart Cities of The Future: 5 Ways Technology Is Transforming Our Cities. Retrieved from http://www.forbes.com on 30/07/2021.

[29] Anas Basalamah, et al., (2016). Greener and Smarter Phones for Future Cities: Characterizing the Impact of GPS Signal Strength on Power Consumption, IEEE Access Smart City, 4(1), 858-868.

[30] Daniel Minoli and Benedict Occhiogrosso. (2019). Practical Aspects for the Integration of 5G Networks and IoT Applications in Smart Cities Environments. Hindawi Journal, Wireless Communications and Mobile Computing, 5710834, 1-30.

[31] Leyre Azpilicueta, Peio Lopez-Iturri, Jaime Zuñiga-Mejia, Mikel Celaya-Echarri, et al. (2020). Fifth Generation (5G) mmWave Spatial Channel Characterization for Urban Environments System Analysis. MDPI Journal, Sensors, 20(5360), 1-25.

[32] Laura-Diana Radu (2020). Disruptive Technologies in Smart Cities: A Survey on Current Trends and Challenges. MDPI Journal, Smart Cities, 3(1), 1022-1038.

$* * * * * * * * * * *$ 